\title{
On the capacity of high, moderate and low earthquake frequency content to cause global drift ratio at level-2 of structural performance
}

\author{
Widodo Pawirodikromo*) \\ Department of Civil Engineering and Disaster Risk Management, Islamic University of Indonesia, Yogyakarta, Indonesia
}

\begin{abstract}
The earthquake (EQ) frequency content can be high, moderate or low frequency, mainly depends on epicenter's distance and local soil conditions. The EQ frequency content will affect on the inelastic response of building structures. According to Vision 2000 and FEMA 356 under particular hazard level, the building is expected to perform structural response either fully operational, immediate occupancy, life safety or near collapse. Numerical investigation of 10-stories mid-rise reinforced concrete frame structure subjected to variations of the earthquake frequency contents has been conducted. The building model is assumed to be located at Yogyakarta on the soft soil condition. The building model it was shaken by various EQ frequency contents and maximum ground accelerations (PGA) until approaching the global drift ratio (GDR) of $0.50,0.75,1.00,1.25,1.50,1.75$ and 2.00 $\%$. Result of investigation show that the EQ high frequency is almost impossible to cause GDR $\pm 2.0 \%$ since it needs PGA as high as 4.01g. Under the possible maximum recorded PGA in the field, the only EQ with low frequency content which has capacity to cause maximum GDR reaches $\pm 2.0 \%$. or at maximum of structural performance level. Between GDR and overall damage index (ODI) is linearly correlated, however boundaries of the performance levels according to GDR and ODI does not meet at the same point.
\end{abstract}

\section{Introduction}

The design of earthquake (EQ) resistant structures has undergone evolution from traditional forced based seismic design (FBSD) to now so called performance based on seismic design (PBSD). The evolution of the design method is due to the fact that there is an increased risk to be retained by the public after several major earthquakes occurred since the 1990's [1]. Similar statement was also presented by [2]. The previous method i.e. FBSD actually has already successfully protected the fatalities under earthquake but the cost of repairing the structure were unexpectedly high. This is because in the FBSD the main objective of the method is to provide required strength and ductility under particular level of seismic hazard to provide for life safety only. Therefore, it should be given an alternative in the selection of a design method that gives better protection not only life safety but also loss of wealth. This means that it should be given level of structural damage other than the Life Safety (LS).

It has been presented by researchers that in the PBSD the design criteria as expressed in term of performance objectives when the structure is subjected to particular level of seismic hazard [2]. There are several types of

\footnotetext{
*) Corresponding author : widodo355@gmail.com 785110201@uii.ac.id
}

performance objectives that have been proposed, however, according to Vision 2000 or FEMA 356 the performance states or performance targets are fully operational (FO), immediately Occupied (IO), life safety (LS) and near collapse (NC) or collapse prevention. These performance targets are for the structure that respectively subjected to frequent, occasional, rare and very rare earthquake occurrence.

Depending on many variables, EQ ground motion may fall into the high, medium or low frequency content. Results that have been obtained researchers indicated that the EQ frequency is one of the important parameter of the damage potential of earthquake ground motion. The study of the seismic performance evaluation of reinforced concrete structure was also conducted by [3]. The 10stories reinforced concrete moment resisting fame was used as structural model. In this study, the push over method/analysis was used to evaluate the seismic structural performance. The plastic hinge rotation was used to be criteria in determination of the performance levels. Result of the study indicated that types of control either displacement or forced control affected the formation of plastic hinges in the level-level of performance levels.

Review, development and implementation of the PBSD of reinforced concrete structure by using several Capacity-Demand non-linear static or push-over methods 
has been conducted by [4] The story drift ratio and plastic hinge rotation have been used as criteria for structural performance levels. The quantitative values of plastic hinge rotation were presented at level-level of structural damage /performance levels at PBSD. Research with the similar method and continuation of previous research has also been done and reported by [5]. The structural models are similar to the previous model i.e 4-story reinforced concrete moment resisting structure. In this study, the stiffness damage index, global drift ratio and base shear as damage parameter based on stiffness degradation of the member were used. The variation of the structural stiffness over the GDR and plot between GDR and stiffness damage index by considering the PBSD performance levels were presented as the main result of the investigation.

In contrast to previous studies, this study has identified the EQ with high frequency (HF), moderate frequency $(\mathrm{MF})$ and low frequency (LF) content in relation to its capacity to cause/resulting global drift ratio (GDR) according to performance levels in the PBSD by using inelastic time history analysis. The GDR was chosen as main dependent variables since the criteria for performance objectives according to Vision 2000 or FEMA 356 is based on GDR. In the inelastic dynamic analysis, the structure was designed according to full ductility principle so that only stiffness degradation is allowed and no strength degradation of the member was assumed. In this study, 3-scenarios have been used: 1) structural response due to high, moderate and low frequency content with same GDR then to be compared, 2) the structure response due to the same PGA at EQ high, moderate and low frequency are also compared and 3 ) plotting between GDR and ODI that includes performance levels.

\section{The Capacity of Earthquake Ground Motions}

The capacity of earthquake (EQ) ground motion has been discussed and scrutinized since a long time [6,7]. The capacity of earthquake ground motions is sometimes also defined as the damage potential of EQ ground motions as presented by [8]. The ground motion capacity or the EQ damage potential will be affected by its earthquake characteristics. The EQ self characteristics then also called the engineering characteristics of earthquake ground motions as discussed by [9] and lately is developed to become ground motion or seismic intensity measures [10].

Categorization of seismic intensity measures has been proposed by researchers [8]. In general the seismic intensity measures can be classified into peak values, earthquake duration, intensity and seismic energy dissipation [8] families. Meanwhile according to [11] the seismic or ground motion intensity measure can also be classified into acceleration, spectral and velocity based families. In other side, the seismic intensity measures can also be classified in three big-families [12] i.e according to non structural intensity measure, structural intensity measure and structural response measure families. All of proposed intensity measures were addressed to the capacity or damage potential of the EQ ground motions.

\section{Structural Performance Levels}

The definitions of structural performance levels at PBSD have been presented at any occasions including the criteria for performance levels as presented in Table 1. Fully operational (FO) is the condition where the building is expected to sustain or no damage of the structure and non-structural elements. The building is then suitable for a normal occupancy or fully operational after earthquake with the extremely low of Life Safety risk. Immediately Occupancy (IO) is the second level of structural performance where the building is expected to no damage of structural elements but a minor damage of the nonstructural elements may occur. Even though the building is in the status of IO usage-ability, however, some repair and cleanup of small debris in general is still needed. This structural performance is included in very low risk category.

Life Safety (LS) is another performance that it has specific meaning. Life Safety performance level does not mean that there is no possibility of injuries as an impact of moderate structural damage, but there may be some. At the level of moderate damage, the structural is expected still stable [13] and can be economically repaired, meanwhile replacement to non structural elements may be strongly required. Collapse Prevention (CP) or near collapse (NC) is the condition where an extensive damage of structural and non structural elements may have been occurred. However, for protecting the fatalities the partial or total collapse of the structure is not expected. Loss of the building cannot be avoided since repairing of the structure is likely not economical.

Table 1. Performance levels vs .GDR and ODI

\begin{tabular}{|c|c|c|c|c|c|}
\hline FO & IO & LF & NC & CL & Ref. \\
\hline \multicolumn{5}{|c|}{ Global Drift Ratio, GDR (\%) } & \\
\hline$<0,20$ & $<0.50$ & $<1.50$ & $<2.50$ & $>2.50$ & {$[2]$, Vision } \\
& & & & & 2000, \\
\hline \multicolumn{7}{|c|}{ Structural/Overall Dmg. Index (ODI) } & \\
\hline 0.05 & 0.20 & 0.40 & 0.80 & $>1.00$ & {$[14]$} \\
\hline$<0.20$ & $<0.40$ & $<0.60$ & $<0.70$ & $>0.70$ & {$[15]$} \\
\hline
\end{tabular}

\section{The Global Damage Indicators}

In the design of earthquake resistant structure, damage of structural element is still permitted under particular level of hazard level. Damage can be addressed to the element, story as well as structural or global damage. Damage to structural elements begins when under the seismic excitation the element's response has 
reached beyond the elastic limit and quantitatively presented as a damage index and has been proposed by researchers as presented by $[3,16]$.

A side of structural damage index, the global structural response such as the global drift ratio, the base shear and the hysteretic energy dissipation can also be utilized as the global damage indicators. The global drift ration has been used as a main indicator in the implementation of the performance based seismic design. There are dozens concept of element damage index formulation, however, the element damage index according to [17] has been used and is presented as,

$$
E D I=\frac{d_{m}}{d_{u}}+\beta \frac{\int d E}{F_{y} \cdot d_{u}}
$$

Where $\mathrm{d}_{\mathrm{m}}$ and $\mathrm{d}_{\mathrm{u}}$ are maximum and ultimate displacement, $\beta$ is cyclic parameter, $F_{y}$ is yield force and $E$ is dissipated hysteretic energy

Mean while according to [16] the story damage index (SDI) and the structural or overall damage index (ODI) can be computed respectively by,

$$
\begin{array}{r}
S D I=\frac{\sum_{i=1}^{n} E D I_{i} \cdot E_{i}}{\sum_{i=1}^{n} E_{i}} \\
O D I=\frac{\sum_{i=1}^{n} S D I_{i} \cdot E_{s t, i}}{\sum_{i=1}^{n} E_{s t, i}}
\end{array}
$$

Where $E_{i}$ is the member dissipated energy and $E_{s t, i}$ is the story dissipated energy.

\section{Method of Investigation}

In this investigation, a reinforced concrete (RC) frame building structure with 10-stories was used as a structural model. The 2-D RC frame as shown in Fig. 1) is used as a planar frame model and was designed according to concrete compressive strength of $\mathrm{f}_{\mathrm{c}}=30 \mathrm{MPa}$ and steel bar yield stress $\mathrm{f}_{\mathrm{y}}=400 \mathrm{MPa}$. The building was assumed located at Yogyakarta, Indonesia region on the soft soil site. The RC frame was designed according to [18] and [19]. Three beam spans have same size where the vertical distribution of the beam's size over the building height is shown in the figure. In addition all line-columns have similar size and the vertical distribution of column's sizes is presented as well in the figure.

The building structure was excited by 3 -earthquake motions with high (HF), moderate (MF) and low frequency (LF) contents as shown in Fig.2). The categorization of earthquake frequency content according to [20] was used. The inelastic response of the structure was considered and the Ruaumoko [21] computer package program was used in the inelastic structural analysis. According to data, the Sendai earthquake of March 11, 2011 has recorded one of the highest ground acceleration during earthquake. Based on data from 19 strong motion seismograph networks of Japan K-net and Kik-net the ground acceleration varies and reaching the highest value of $\sim 3 \mathrm{~g}$ [22]. In relation of this condition, The Japanese seismologist identified that the high of earthquake ground acceleration is the result of high amplification of soil layer during the major earthquakes. The maximum ground accelerations were scaled-up and scaled-down in such way it causes the global drift ratio as it expected. Meanwhile according to [23], the maximum PGA from the 2011 Tohuku earthquake reached the maximum of $1.0-2.0 \mathrm{~g}$.

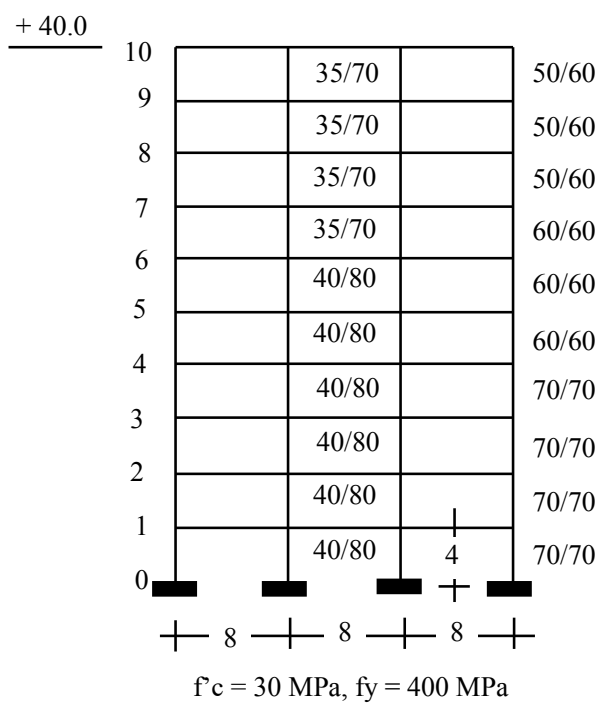

Fig.1. The structural Model
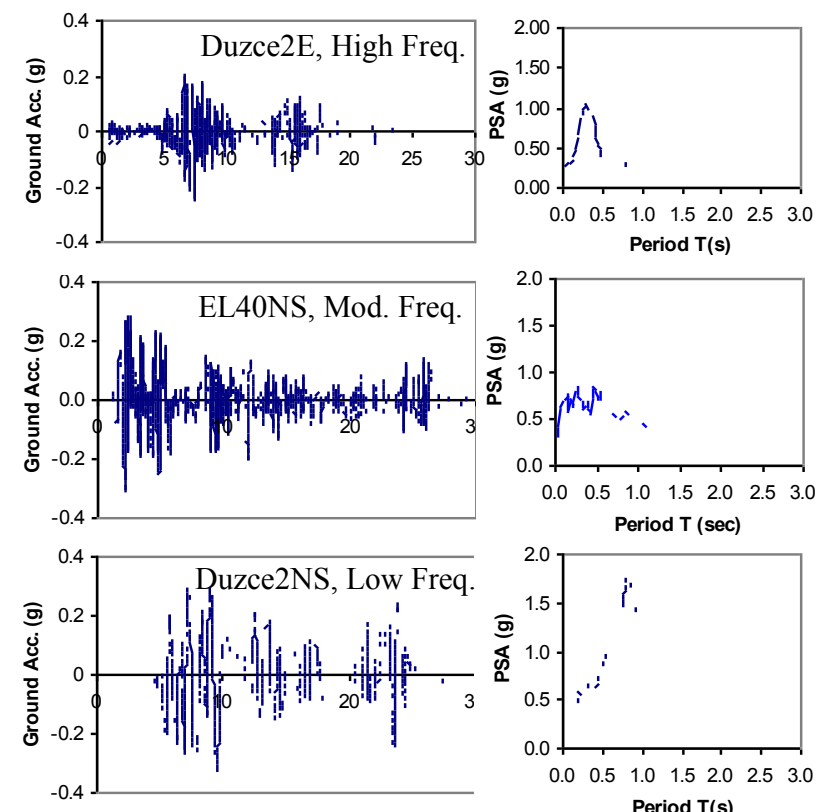

Fig.2. The earthquake Excitations 


\section{Results and Discussions}

\subsection{Global drift ratio vs global damage Indicators}

The relationship between GDR and the GD is presented in Fig. 3 and numerically is presented in Table.2. Due to limiting space, Table 2 only presents the numerical relationship between GDR and GDI for earthquake low frequency (LF) content. As clearly shown in Fig.3 that to cause NC or CL performance level ( $\pm 2 \%$ of GDR), the EQ with LF content only needs $\pm 0.69 \mathrm{~g}$. whereas for moderate and high frequency content respectively require $\pm 1.52 \mathrm{~g}$ and more than $4.01 \mathrm{~g}$. This is because the EQ with LF frequency content is closer to the structural natural frequency as compared to EQ with $\mathrm{HF}$ and MF contents.

As discussed earlier that it was not easy to an earthquake to cause ground acceleration as high as $4.0 \mathrm{~g}$. According to [22] the maximum PGA of the 2011 Sendai megathrust earthquake reached $\pm 3 \mathrm{~g}$, meanwhile PGA of the M6.9 1995 Kobe strike -slip earthquake was only $0.818 \mathrm{~g}$ [24]. Meanwhile according to [25] the maximum recorded PGA within $10 \mathrm{~km}$ from the epicenter of the 2011 Christchurch strike slip earthquake was $1.41 \mathrm{~g}$. Very high PGA is commonly as a result of megathrust earthquake where the epicenter is far away from the site. After arriving at site soil deep deposit that possible to

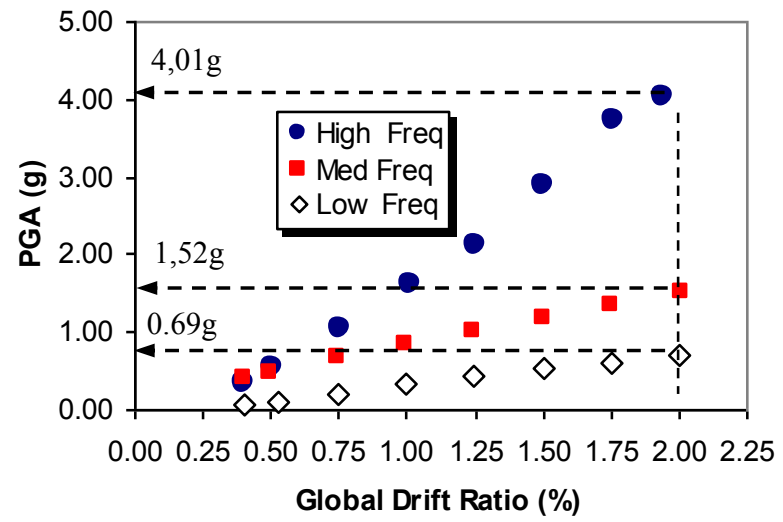

Fig.3. Global Dift Ratio (GDR) vs PGA

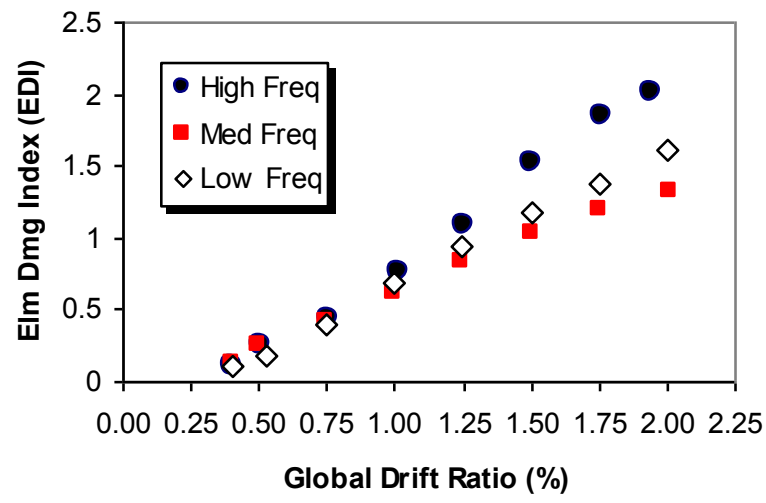

Fig.5. The GDR) vs Element damage Index (EDI) have high amplification, the earthquake high frequency content is usually already modified by layered soil to become low frequency at ground surface.

Table 2. GDR vs Global Damage Indicator (LF)

\begin{tabular}{|c|c|c|c|c|c|}
\hline GDR & PGA $(\mathrm{g})$ & BS(tf) & HE & EDI & SDI \\
\hline 0.40 & 0.081 & 214.70 & 9.10 & 0.116 & 0.140 \\
\hline 0.50 & 0.116 & 234.94 & 30.38 & 0.186 & 0.167 \\
\hline 0.75 & 0.211 & 285.40 & 109.64 & 0.403 & 0.343 \\
\hline 0.85 & 0.261 & 307.75 & 157.28 & 0.518 & 0.397 \\
\hline 1.00 & 0.341 & 337.86 & 249.53 & 0.683 & 0.520 \\
\hline 1.25 & 0.441 & 375.89 & 395.45 & 0.937 & 0.710 \\
\hline 1.50 & 0.524 & 401.89 & 549.60 & 1.173 & 0.881 \\
\hline 1.75 & 0.605 & 429.89 & 725.41 & 1.370 & 1.062 \\
\hline 2.00 & 0.692 & 466.02 & 938.25 & 1.615 & 1.254 \\
\hline
\end{tabular}

Moreover the shallow crustal EQ which closes to site usually possesses high frequency content. By those all reasons and highest recorded PGA on the site, it can be concluded that the EQ with high frequency content is impossible to cause GDR reached higher performance levels of moderate building such as NC or CL, since it needs very high PGA. However, based on the maximum recorded PGA at the 2011 Christchurch earthquake, the moderate earthquake frequency is still possible to cause the highest building performance level.

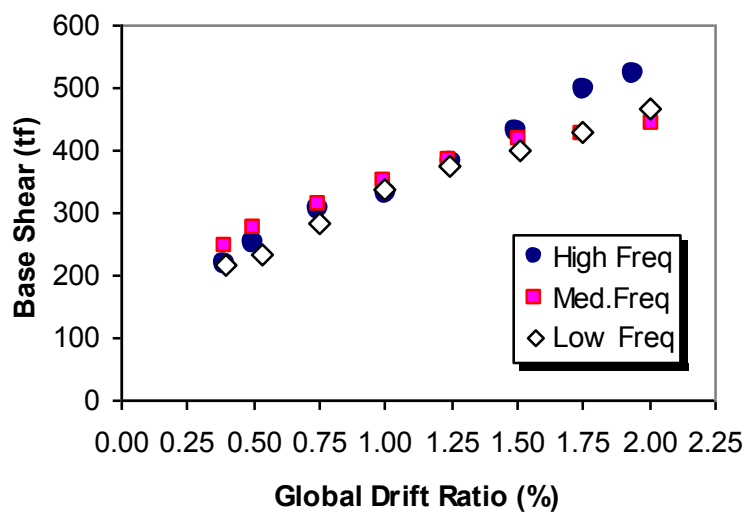

Fig.4. GDR vs. the Base Shear (BS)

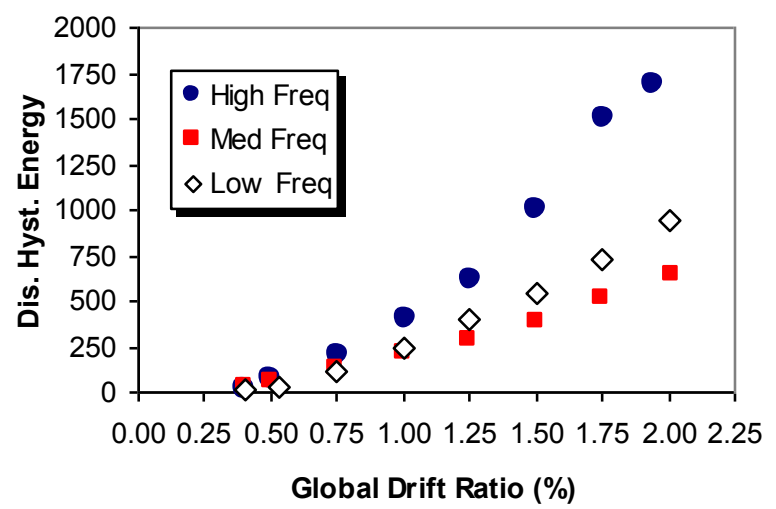

Fig.6. The GDR vs. the Dissipated Hyst. Energy 
Table 3. PGA at level-level structural performance

\begin{tabular}{|c|c|c|c|c|}
\hline FO & IO & LF & NC & CL \\
\hline \multicolumn{5}{|c|}{ Global Drift Ratio, GDR (\%) } \\
\hline$<0,20$ & $<0.50$ & $<1.50$ & $<2.50$ & $>2.50$ \\
\hline \multicolumn{5}{|c|}{ The required PGA (g) } \\
\hline$<0.15 \mathrm{~g}$ & $<0.55 \mathrm{~g}$ & $<2.83 \mathrm{~g}$ & $<4.0 \mathrm{~g}$ & - \\
\hline$<0.20 \mathrm{~g}$ & $<0.45 \mathrm{~g}$ & $<1.0 \mathrm{~g}$ & $<1.5 \mathrm{~g}$ & - \\
\hline$<0.10 \mathrm{~g}$ & $<0.11 \mathrm{~g}$ & $<0.50 \mathrm{~g}$ & $<0.60 \mathrm{~g}$ & - \\
\hline Structural/Overall Damage Index (ODI) \\
\hline 0.05 & \pm 0.30 & \pm 0.40 & \pm 0.75 & $>1.00$ \\
\hline \multicolumn{5}{|c|}{ The required PGA (g) } \\
\hline $\pm 0.30 \mathrm{~g}$ & $\pm 0.80 \mathrm{~g}$ & $\pm 1.25 \mathrm{~g}$ & $\pm 1.80 \mathrm{~g}$ & $\pm 2.85 \mathrm{~g}$ \\
\hline$<0.10 \mathrm{~g}$ & $\pm 0.35 \mathrm{~g}$ & $\pm 0.90 \mathrm{~g}$ & $\pm 1.20 \mathrm{~g}$ & $\pm 1.52 \mathrm{~g}$ \\
\hline$<0.10 \mathrm{~g}$ & $\pm 0.20 \mathrm{~g}$ & $\pm 0.32 \mathrm{~g}$ & $\pm 0.50 \mathrm{~g}$ & $\pm 0.60 \mathrm{~g}$ \\
\hline
\end{tabular}

As presented in Table 1 that the structural performance levels can be determined approximately by the GDR or by ODI. In Table 3 is presented the required PGA at levellevel of structural performance based on global drift ratio (GDR) or overall damage index (ODI) for earthquake high frequency (HF), moderate frequency (MF) and low frequency (LF). Result of the analysis indicated that the required $\mathrm{PGA}$ to reach each performance levels with indicator GDR is determined based on applied earthquake excitation during analysis. However, the required PGA to cause each performance levels based on ODI criteria could not determined exactly, thus the required PGA's as shown in Table 3 are determined based on interpolation.

\subsection{Story horizontal displ. and story drift ratio}

Relationship between GDR and the structural base shear caused by the high, moderate and low frequency contents is presented in Fig.4). As clearly shown in the figure that the base shear does not sensitive to the earthquake frequency content as indicated by relatively close value of base shear at every level of GDR. As compared to BS, the Element Damage Index (EDI) as presented in Fig.5) is more sensitive to GDR particularly at higher values. The element damage index was determined by using Eq.1). As shown in the figure that the EQ low frequency content with lower PGA even causes higher EDI than the EQ moderate frequency content. A similar and even more sensitive result is presented in Fig.6) i.e relationship between GDR and dissipated hysteretic energy. Higher dissipated hysteretic energy of the EQ low frequency content with lower PGA as compared to the EQ moderate frequency content is the result of resonant resonance effects.
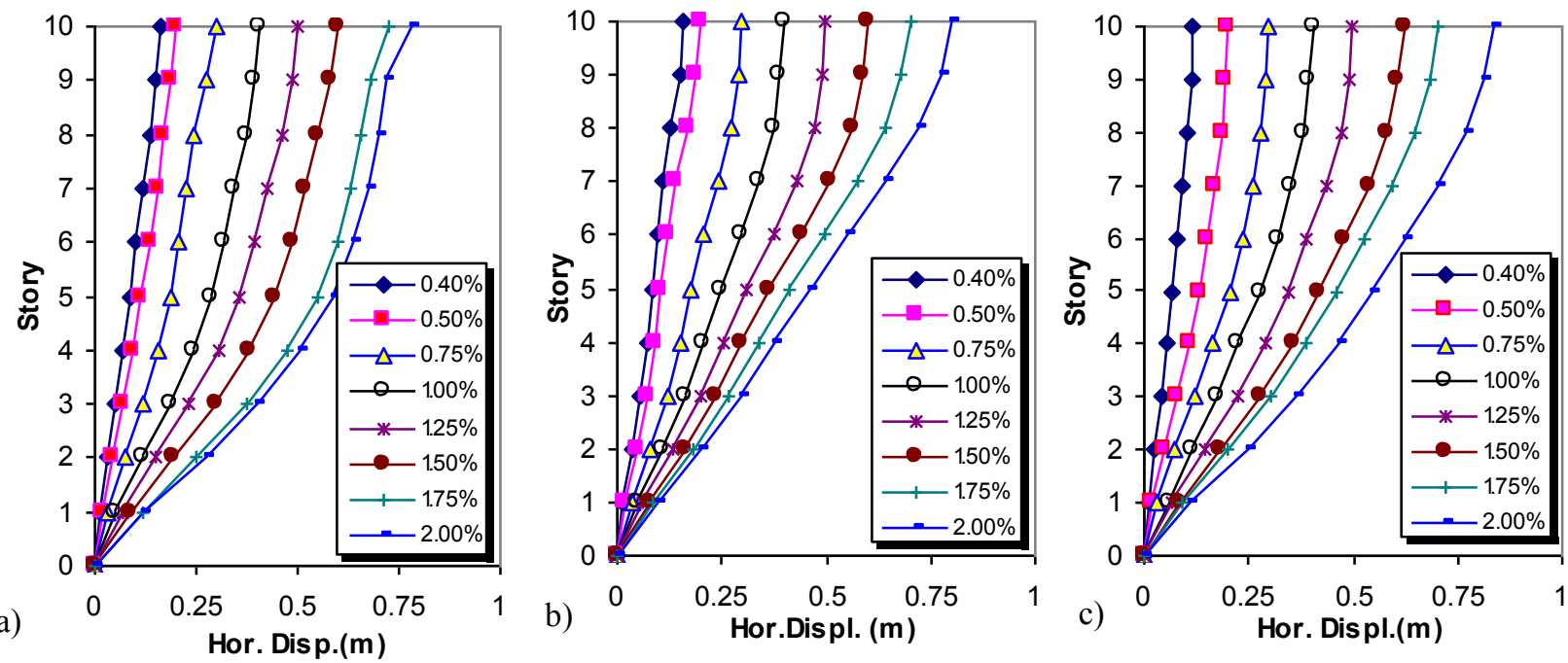

Fig.7. The maximum story horizontal displacement caused by: a) high, b) moderate and c) low EQ frequency content

The story horizontal displacement subjected to high, moderate and low frequency are presented in Fig.7). It should be noted that those story horizontal displacements at $\pm 2 \%$ GDR and its story drift ratio as presented in Fig. 8 are caused by $\pm 4.01 \mathrm{~g}, \pm 1.52 \mathrm{~g}$ and $\pm 0.69 \mathrm{~g}$, respectively for high, moderate and low earthquake frequency content. It clearly shown in Figs.7a) and 8a) that higher response effect appears on the 10-stories or mid-rise building model caused by the EQ higher frequency content. Mean while, the domination of the first mode on the story horizontal displacement caused by EQ low frequency content clearly appears in Fig.7c). Higher story drift ratio as shown in Fig.8a) again is caused by applying very high PGA as high as $4.01 \mathrm{~g}$ and only $\pm 1.52 \mathrm{~g}$ and $\pm 0.69 \mathrm{~g}$ causes the story drift ratio as presented in Figs.8b) and 8c).

\subsection{PGA vs. Global Damage Indicators}

The effects of the capacity of EQ frequency contents to the structural response can also be presented the 
relationship between PGA as independent variable with Global damage indicator as variable dependent. Relationship between PGA and GDR is presented in Fig.9a). It is clearly shown in the figure that to cause GDR $\pm 2 \%$ the EQ high frequency contents requires PGA as high as $4.01 \mathrm{~g}$, meanwhile only require $\pm 1.52 \mathrm{~g}$ and $\pm 0.69 \mathrm{~g}$ respectively for moderate and low frequency content. Meanwhile, the relationship between PGA and $\mathrm{BS}$ is presented in Fig.9b). Unlike the previous results, the BS is very sensitive to the PGA. Similar results are also found in the relationship between PGA with EDI as well as PGA and dissipated hysteretic energy (DHE) as presented respectively in Figs 9c) and 9d).

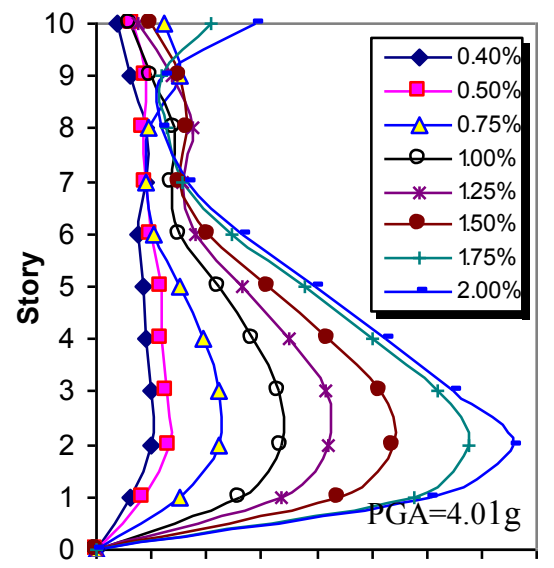

a) $\begin{array}{lllllllll}0.0 & 0.5 & 1.0 & 1.5 & 2.0 & 2.5 & 3.0 & 3.5 & 4.0\end{array}$

Drift Ratio (\%)

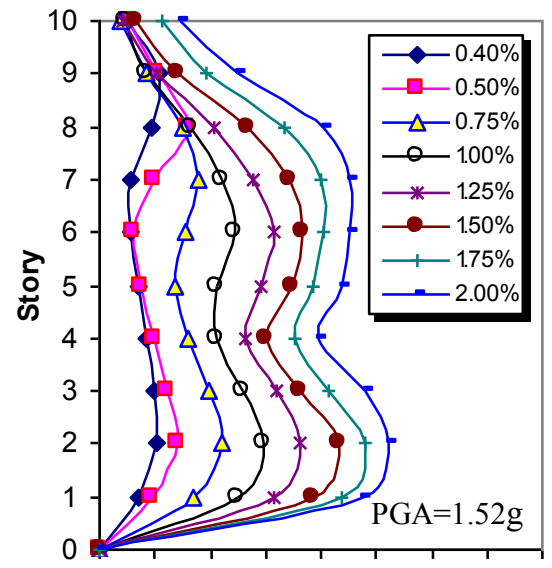

$\begin{array}{lllllllll}0.0 & 0.5 & 1.0 & 1.5 & 2.0 & 2.5 & 3.0 & 3.5 & 4.6\end{array}$ b)

Drift Ratio (\%)

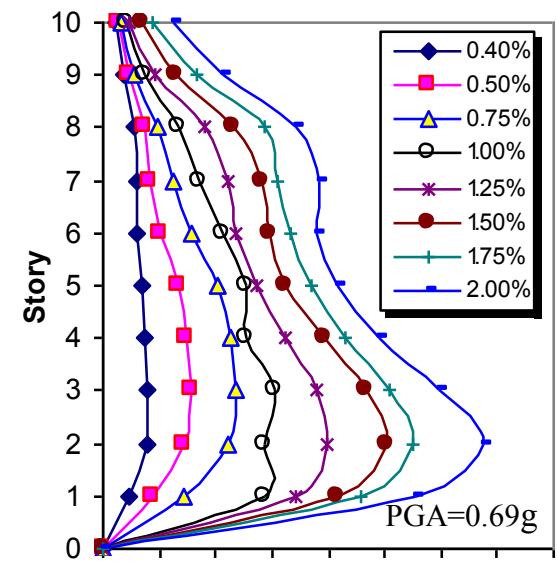

$\begin{array}{lllllllll}0.0 & 0.5 & 1.0 & 1.5 & 2.0 & 2.5 & 3.0 & 3.5 & 4.0\end{array}$

c) Drift Ratio (\%)

Fig.8. Story drift ratio caused by: a) high, b) moderate and c) low EQ frequency content

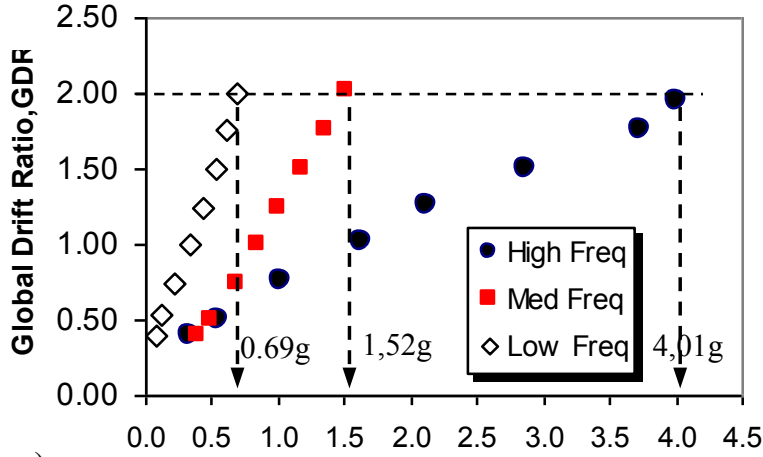

a)

Peak Grounf Acc. (g)

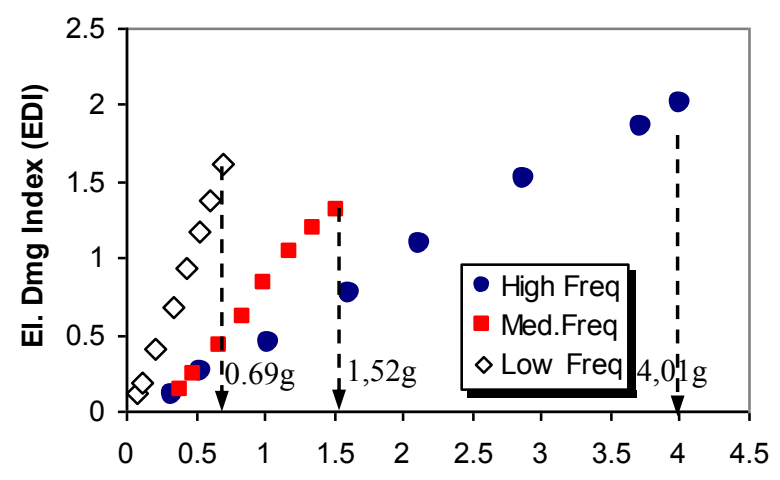

c)

Peak Ground Acc. (g)
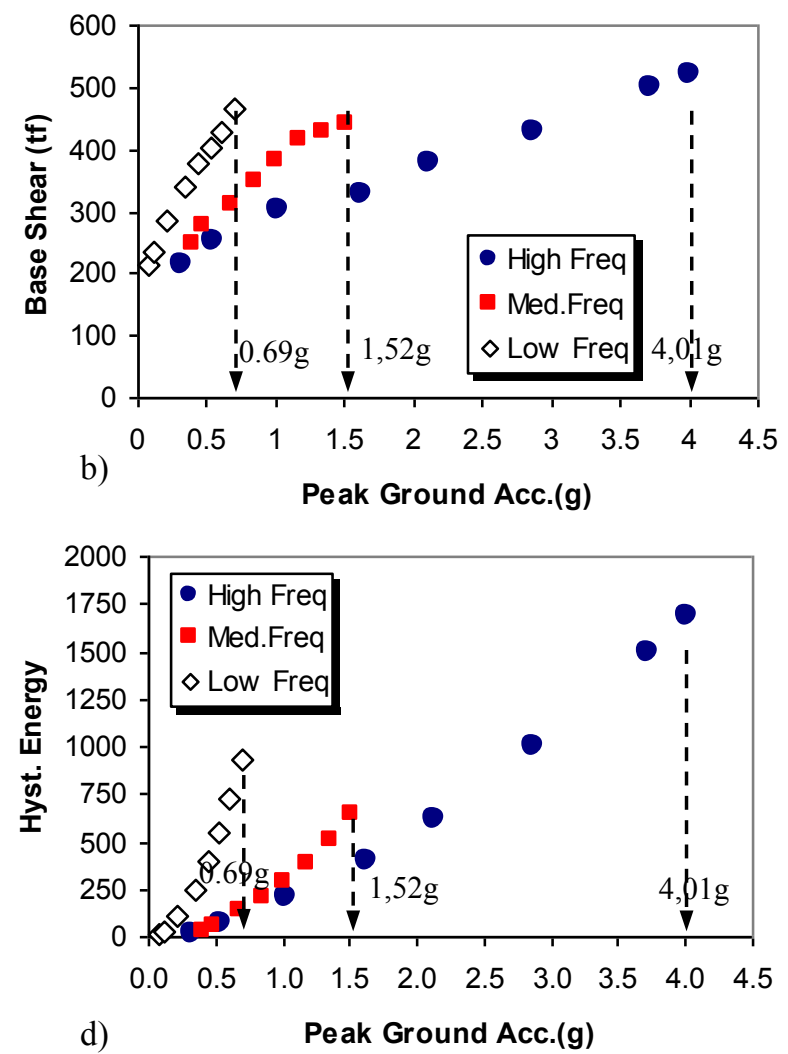

Fig.9. PGA vs: a) roof hor. displacement, b) base shear, c) EDI and d) hysteretic energy dissipation 


\subsection{Roof horizontal displacement and hysteretic dissipated energy}

As shown in Fig.1) that total height of the structure is $40 \mathrm{~m}$, therefore when the gobal drift ratio is expected to be $\pm 2 \%$ then the roof horizontal displacement will reach \pm $0.80 \mathrm{~m}$. The time histories of roof horizontal displacement at $\pm 2 \%$ GDR for EQ high, moderate and low frequency are presented in Figs 10a), 10d) and $10 \mathrm{~g}$ ) respectively. As shown in the figures that the maximum roof horizontal displacement reaches $\pm 0.80 \mathrm{~m}$ which is cuased by PGA $=$ 4.01g of EQ high frequency and $\mathrm{PGA}=1.52 \mathrm{~g}$ and $\mathrm{PGA}=$ $0.69 \mathrm{~g}$ for moderate and low frequency respectively.

The hysteretic loops of the outer column's base that is caused by EQ high, moderate and low frequency are presented in Figs 10b), 10e) and 10h) respectively. It is clearly shown in the figure that the column is dominated by axial load damage as indicated by reducing the column's stengths. It is necessary to enlarge the column's size to avoid the axial load damage domination of the columns. Meanwhile, the seismic energy dissipations of the structural model subjected to $\mathrm{PGA}=4,01 \mathrm{~g}, \quad \mathrm{PGA}=$ $1.52 \mathrm{~g}$ and $\mathrm{PGA}=0.69 \mathrm{~g}$ to cause $\pm 2 \%$ GDR are presented in Figs.10c), 10f) and 10i) respectively. According to Fig.6), the dissipated hysteretic energy caused by the EQ low frequency with $\mathrm{PGA}=0.69 \mathrm{~g}$ even greater than caused by EQ moderate frequency with PGA $=1.52 \mathrm{~g}$.

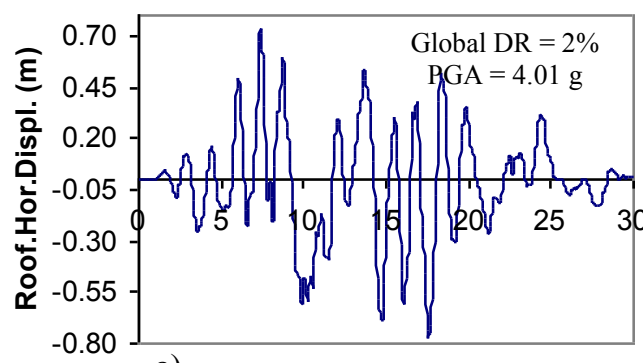

a)

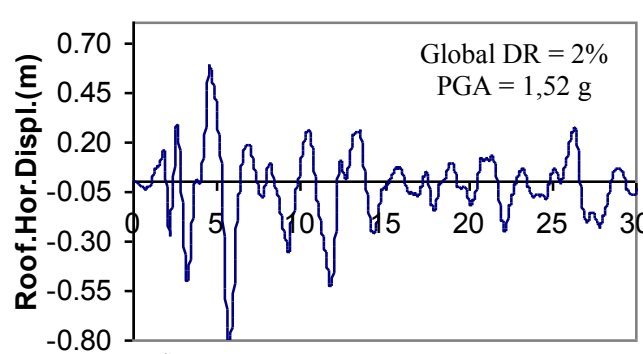

d)

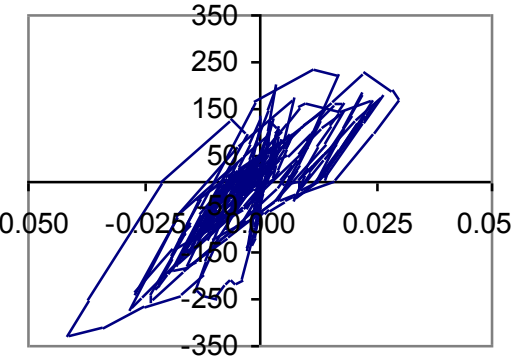

b)

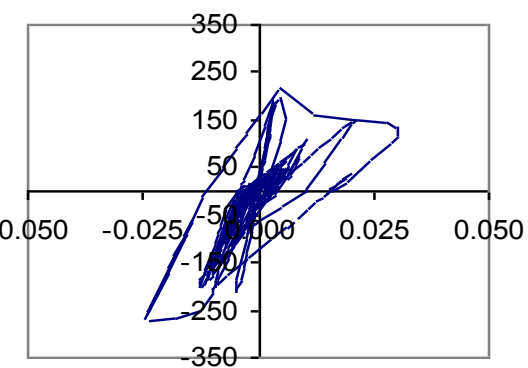

e)

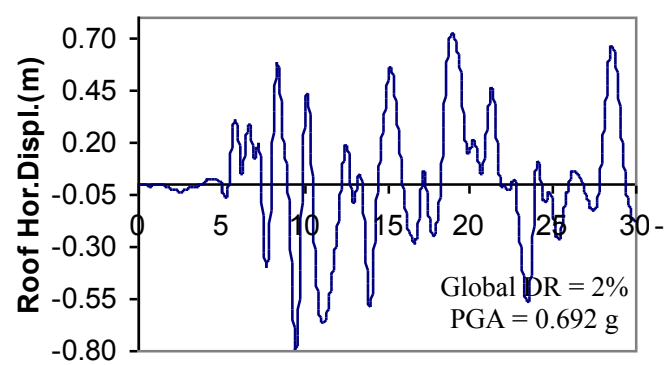

g)

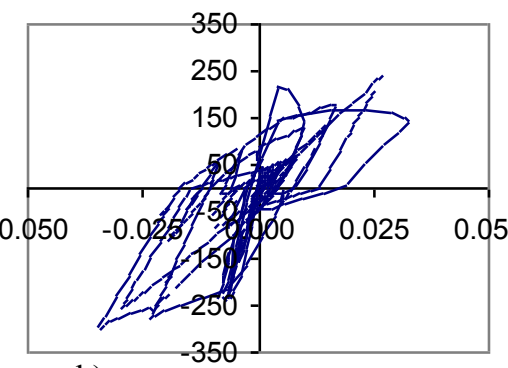

h)
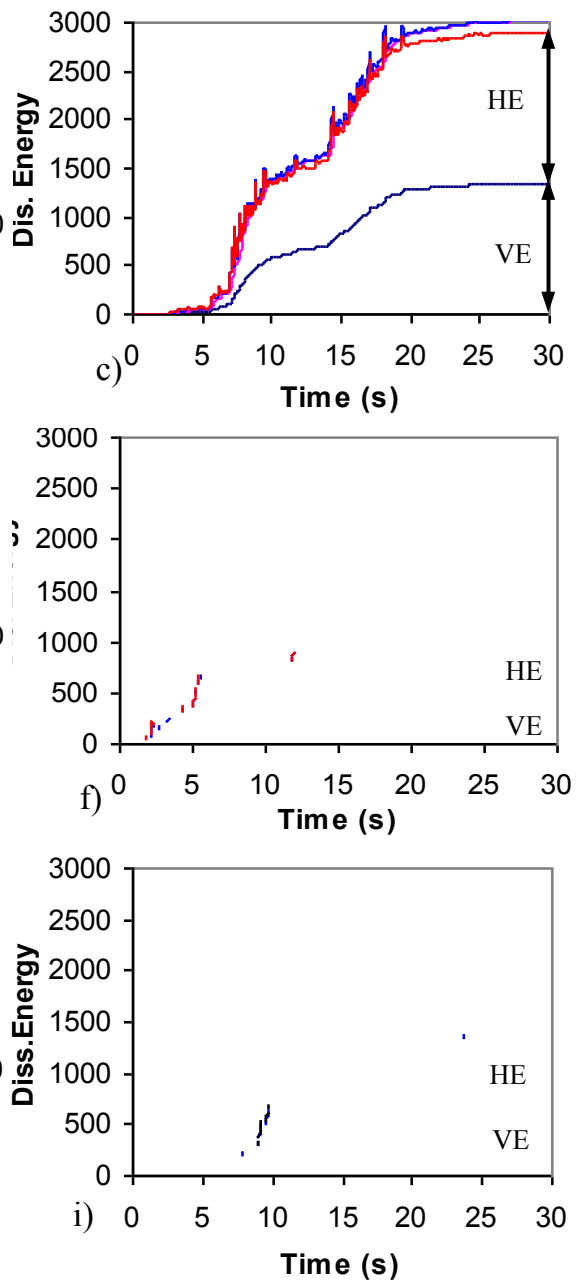

Fig.10. Roof horizontal displacement, hysteretic loops and energy dissipation

\subsection{The Structural response by the same of PGA}

The structure response as presented above is the structure response at the level-levels of structural damage with the GDR is the independent variable. The results as presented in Fig 11) and Fig.12) are the comparison of the structural response when the PGA is used as the independent variable. The maximum PGA is equal $0.69 \mathrm{~g}$ was taken for EQ high, moderate and low frequency contents. As shown in Fig.11) and Fig.12) the structural response i.e. story horizontal displacement, story drift ratio, element damage index, column's hysteretic loops and energy dissipations caused by EQ high and moderate/ medium frequency are much lower that caused by EQ low frequency. This result indicates that by applying same of PGA the structural response are strongly affected by the earthquake frequency content. 


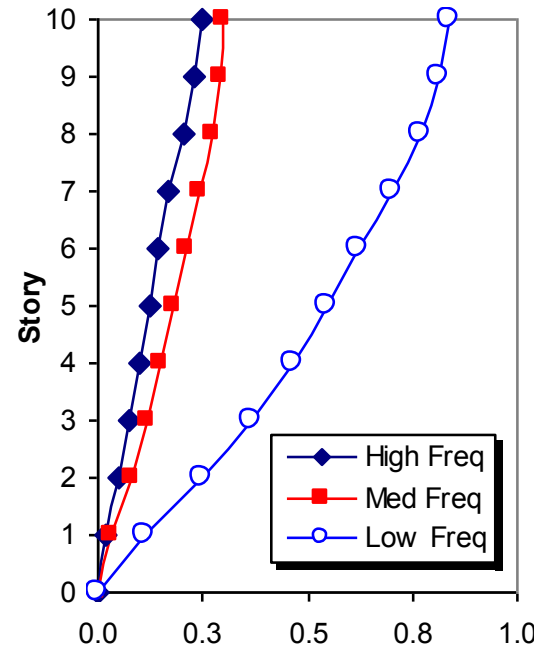

a)

Roof Hor. Displ. (m)

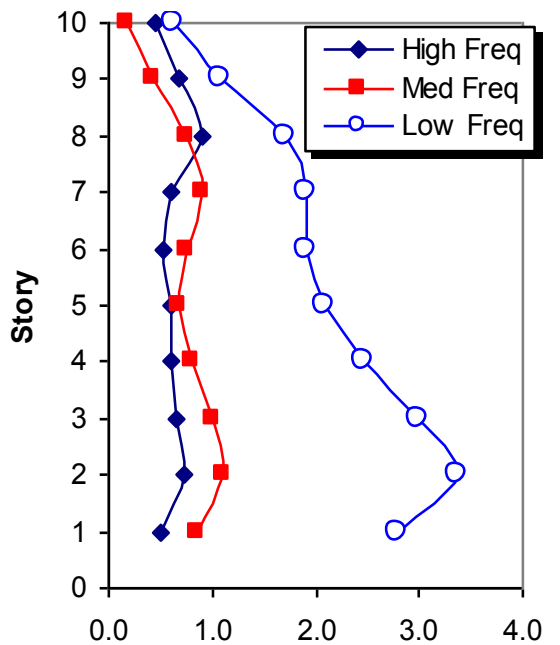

b)

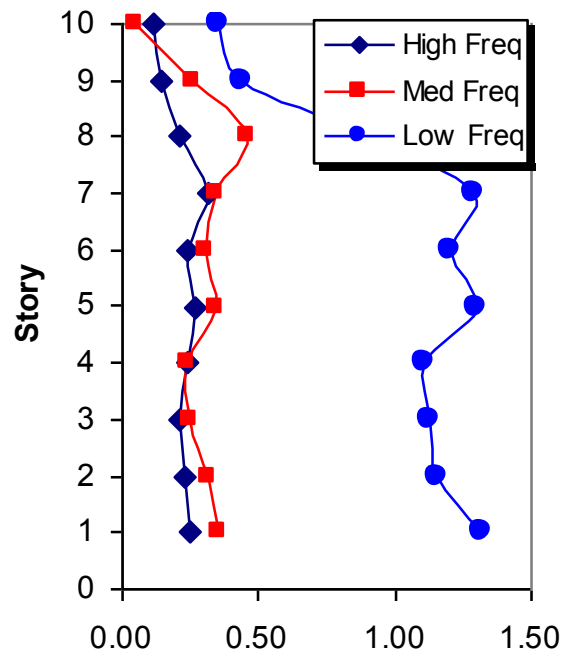

c)

El. Dmg Index (EDI)

Fig.11. Roof horizontal displacement, drift ratio and element damage index.
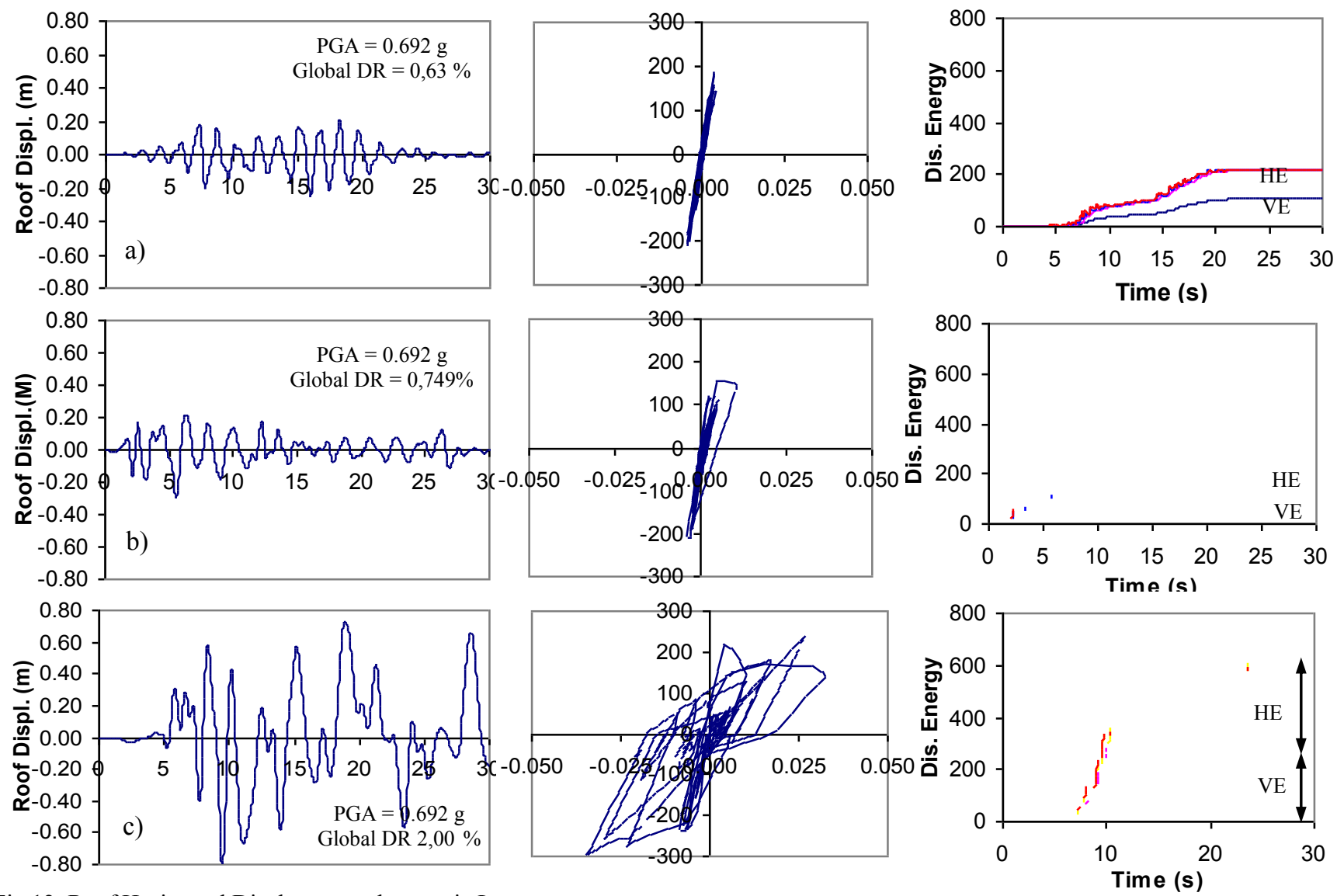

Fig.12. Roof Horizontal Displacement, hysteretic Loops and Energy dissipation

\subsection{Story Damage Index and ODI-GDR relations}

The story damage index (SDI) was calculated by applying Eq.2). The SDI of the structure subjected to the EQ low frequency content for every percent of GDR is presented in Fig.13.a). There is nothing special except the higher the
SDI for the higher of the expected GDR including the performance levels according to [26,27]. The distribution of the SDI along the building height is affected by the beam's strength, building height and EQ frequency content. 

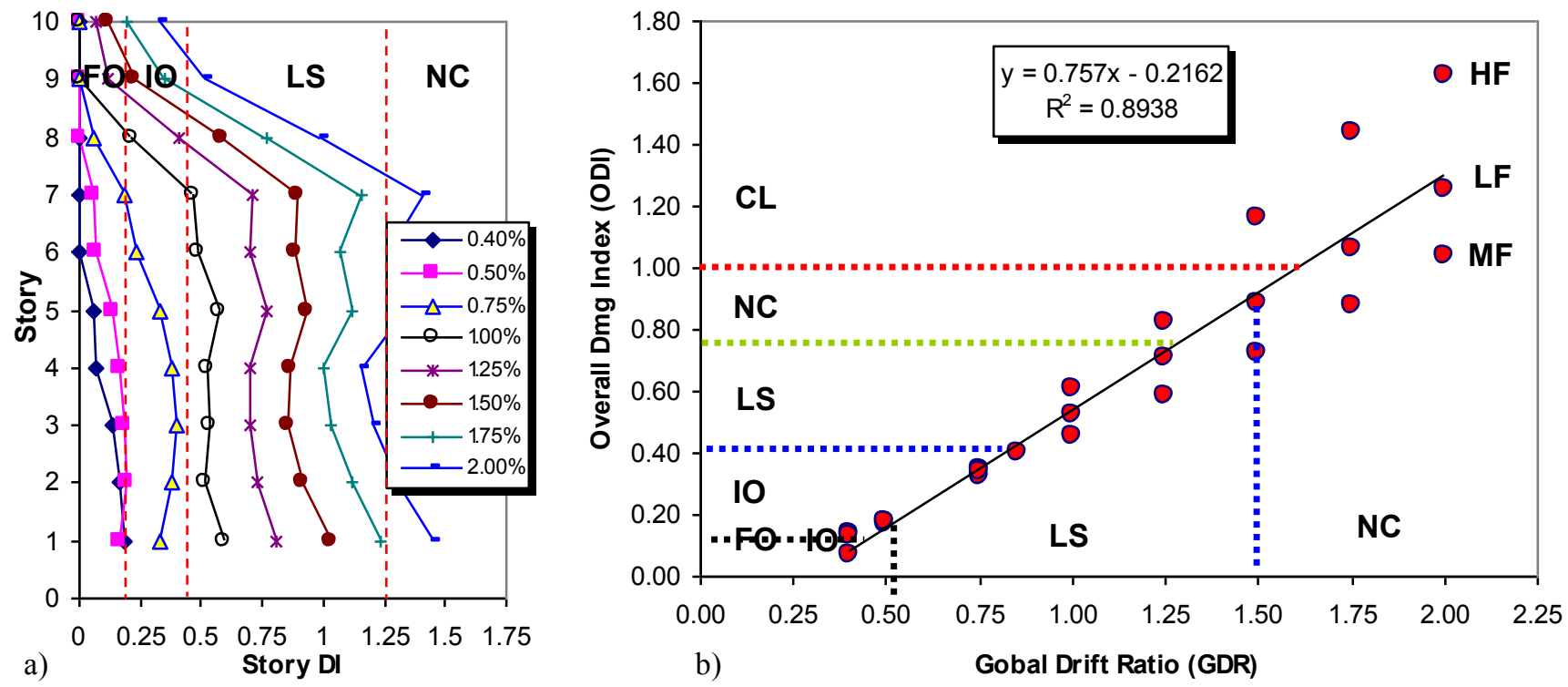

Fig.13. Story damage index and GDR vs. ODI plot

Meanwhile the relationship between GDR and ODI of the structure subjected to the EQ high, moderate and low frequency content is presented in Fig.13b). The figure shows that there is a trend a linear relationship between GDR and ODI for EQ high, moderate and low frequency content. As shown in the figure that the EQ low frequency The level-levels of structural performance are also presented in the figure both based on GDR and ODI criteria as presented in Table 1. As shown in the figure that both GDR and ODI do not meet at the same point in determining the levels of structural performance. Further comprehensive and intensive studies is urgently required

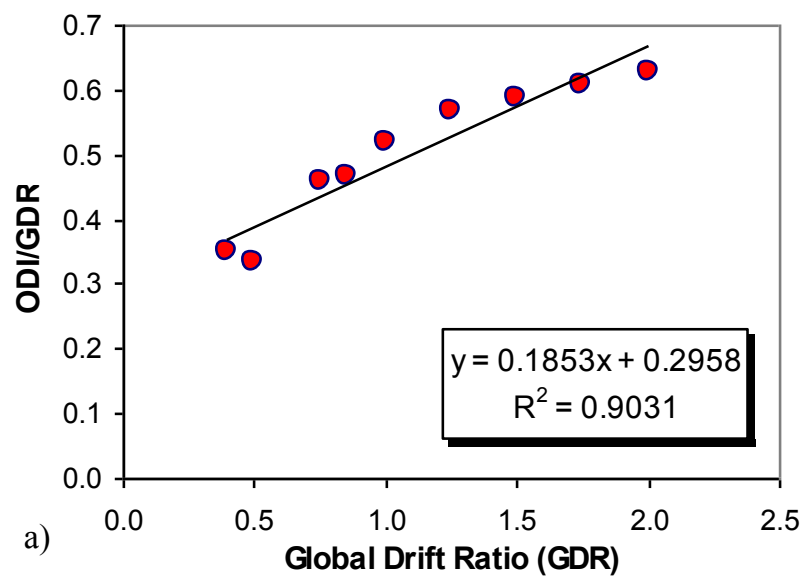

to make clearer insight the correlation between GDR and ODI since the result as presented in Fig.13.b) is only a structure subjected to a single earthquake excitation.

In addition, the plots between the GDR and ratio ODI/GDR are presented in Figs.14). In Fig.14.a) the plot between of them is presented in linear relationship, where in Fig.14.b) the relationship is presented in logarithmic equation. As shown in the figure that the relationship between of the is better presented in term of logarithmic expression since it has higher coefficient of correlation. Similar to above statement, it needs deeper investigation to explore the pattern of the relationship between GDR and ratio ODI/GDR.

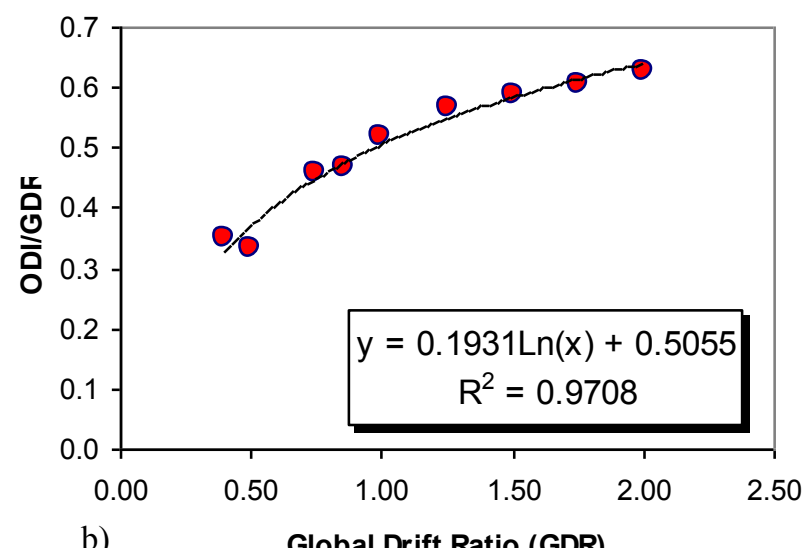

b) Global Drift Ratio (GDR)

Figur1 14. Relationship between GDR and ODI/GDR: a) linear and b) logarithmic expression

\subsection{Overall Damage Index (ODI) Plots}

Plot between PGA and ODI of the structure subjected to EQ low frequency is presented in Fig.15a). Similar as presented in Figs.3) and 13), between PGA and ODI performs linear relationship. This is because the EDI, SDI 
and ODI as presented in EQs.1), 2) and 3) are direct affected by structural response which is depended on PGA. However as shown in Fig.15b), 15c) and 15d)
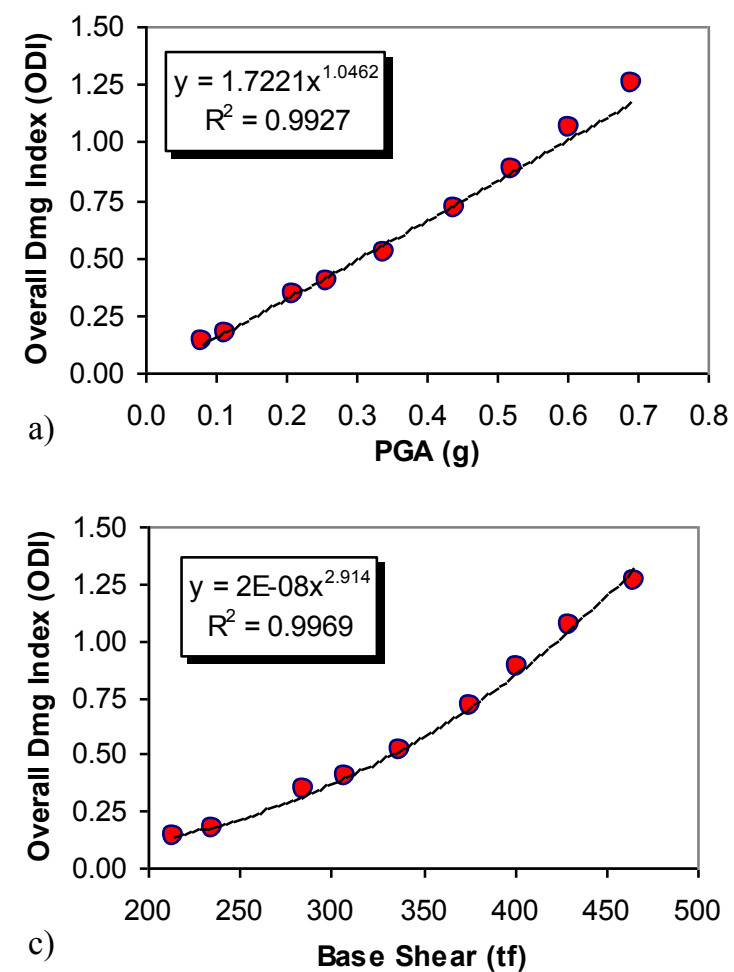

Fig.15. Relationship between damage parameters and overall damage index (ODI)

\section{Conclusions}

A study of the capacity of EQ high, moderate and low frequency content that is likely to cause GDR in accordance with the structural performance levels as in PBSD has been done. The study is still very limited both the number and variation of the structural models and the number and EQ characteristics used. However, based on this study the following conclusions can be drawn.

The RC mid-rise structural model refers to relatively low structural natural frequency, meanwhile the EQ with high, moderate and low frequency were considered as exciting dynamic loads. Result of the study indicated that with respect to $\mathrm{RC}$ mid-rise structure, the EQ with high frequency content is very difficult to cause GDR up to NC or even CL levels due to the required very high PGA. Large megathust earthquakes are generally already heavily attenuated with relatively long epicenter distance so that the recorded PGA's on site are relatively small. The inland closer earthquake, due to its limited accumulated energy, the resulting PGA is also not too large.

When the mid-rise building structure with a relatively low natural frequency is shaken by EQ low frequency content then the structural response will be close to the resonant response. According to the principle of structural relationship between damage indicators or damage parameter with ODI seems not linear but rather than power relationship.
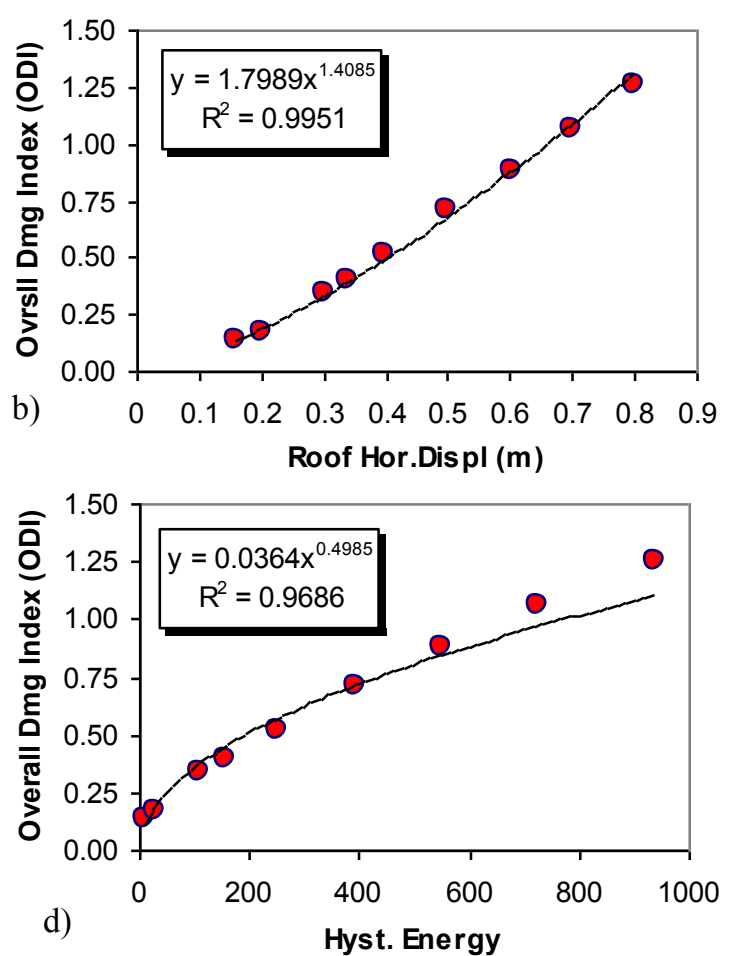

dynamics, the resonant response events will result in a large story horizontal displacement and subsequently will result in great structural damage. Therefore, the EQ low frequency content does not required very high PGA to achieve performance targets as classified in the PBSD.

Relationship between the GDR and the ODI of the structure subjected to EQ high, moderate and low frequency tends to be linear, means that ODI is linearly increase with GDR. As proposed by researchers that GDR and ODI can be used for the quantitative criteria of the performance levels. However, boundaries of the performance levels according to GDR and ODI does not meet at the same point. A more refine, comprehensive and deep study need to be done in applying GDR and ODI criteria for performance levels of the PBSD by considering more variety of structural model and earthquake excitations.

\section{References}

[1] R D Bertero, V V Bertero, Performance Based Seismic Engineering: Development and Application of a Comprehensive Conceptual Approach to Design of Building, Chapter 8 of Earthquake Engineering from Engineering Seismology to Performance Based Engineering, CRC Press, (2004) 
[2] M Bagheri, M Miri, Performance based design in earthquake engineering, $5^{\text {th }}$ International Congress in Civil Engineering, Ferdowsi University of Marshad, Iran, (2010).

[3] H Hastemoglu, Seismic performance evaluation of reinforced concrete frames, IOSR J. Mech. and Civil Eng., Vol.12, Issue 5, 2015, pp.123-131.

[4] M Zameeruddin, K K Sangle, Review on Recent Developments in the Performance Based Seismic Design of Reinforced Concrete Structures. Structures, Vol. 6, (2016), pp.119-133.

[5] M Zameerudin, K K Single, Seismic Damage Assessment of Reinforced Concrete Using NonLinear Static Analyses, J. Civil Eng., 21(4), (2017), pp.1319-1330.

[6] M Rodriguez, A measure of the capacity of earthquake ground motions to damage structures, J. Earthq. Eng. and Struct. Dyn. (EESD), Vol.23, No.5, (1994), pp.627-643.

[7] H B Ozmen, M Inel, Damage potential of earthquake records for RC building Stocks, J. Earthq. and Struct., Vol.10, No.6, (2016), pp.1315-1330.

[8] L Danciu, Development of a system to assess the earthquake damage potential for buildings: Intensiometers, PhD Thesis University of Patras, Greece, (2006), 253p.

[9] H Sucuoglu, A Nurtug, Earthquake ground motion characteristics and seismic energy dissipations, J. Earthq. Eng. and Struct. Dyn. (EESD), Vol. 25, (1995), pp. 1195-1213.

[10] A Elenas, Seismic-Parameter-Based Statistical Procedures for the Approximate Assessment of Structural Damage, Mathematical Problem in Engineering Research Article, (2014), 22p.

[11] N Buratti, A Comparison of the performances of various ground motion intensity measures, The $15^{\text {th }}$ Worlrd Conference on Earthquake Engineering , Lisboa, (2012)

[12] Y Cheng, Intensity measures for seismic response prediction and associated ground motion selection and modification, Doctorate Dissertation, Department of Structural Engineering and Geotechnics, Sapienza University of Rome, (2013).

[13] C Doniga, Performance Based Designed-State of the Art, Faculty of Civil Engineering and Building Sciences, Gheorghe Asachi Technical University of Iasi, (2014).

[14] H Jiang, B Fu, L Chen, Damage control Seismic Design Of Moment Resisting Frame Buildings, J. Asian Arch. and Eng. Build., Vol.12, No.1, (2013), p.49-56
[15] A Bagchi, Evaluation of the seismic performance of Reinforced Concrete Buildings, $\mathrm{PhD}$ Thesis, Department of Civil and Environmental Engineering, Carleton University, Ottawa, Canada, (2001), 257 p.

[16] R Sinha, S R Shiradhonkar, Seismic damage index for classification of structural damage-closing the loop, The $15^{\text {th }}$ World Conference on Earthquake Engineering, Lisboa, (2012).

[17] Y J Park, Ang A H S, Mechanistic Seismic Damage Model for Reinforced Concrete, J. Struct. Eng. Div. ASCE, Vol. 111, No.4, (1995), pp.722-739

[18] SNI 1726, Tata cara perencanaan ketahanan gempa untuk bangunan gedung dan non gedung, Badan Standarisasi Nasional, (2002), 138p.

[19] SNI 2847, Persyaratan beton structural untuk bangunan gedung, Badan Standarisasi Nasional, (2013),p.255

[20] W K Tso, T J Zhu, A C Heidebrecht, Engineering implication of ground motion $\mathrm{A} / \mathrm{V}$ ratio, J. Soil Dyn. and Earthg. Eng., 11,(1992) pp.133-144

[21] A J Carr, Ruaumoko Program Library,University of Canterbury, Christchurch, New Zealand,1998.

[22] Pavlenko, "Physical mechanism of high peak ground acceleration $(>1 \mathrm{~g})$ in strong ground motion (Tohuku earthquake of March 11, 2011 as an example)", The $2^{\text {nd }}$ European Conference on Earthquake Engineering and Seismology, Istanbul Turkey, (2014),

[23] T Furumura T, $\mathrm{S}$ Takemura, S Noguchi, T Takemoto, T Maeda, K Iwai, S Padhy, Strong Ground Motion from the 2011 off-the Pacific Coast - of-Tohuku, Japan (Mw9.0) earthquake obtained from a dense nationwide seismic networks, Landslides, 8, (2011), pp.333-338.

[24] V V Bertero, The Seismological and Engineering aspects of the January 17, 1995 Hyogoken-Nanbu (Kobe) Earthquake, Earthquake Engineering Research Centre, University of Berkeley, California, Report No:UBC/EERC/95/10, 250p.

[25] B Bradley, 22 February 2011 Christchurch Earthquake: Are we adequately characterizing extreme/rare events?, Department of Civil Engineering, University of Canterbury, Christchurch New Zealand, (2011),

[26] A Ghobarah, On drift limits associated with different damage levels, Department of Civil Engineering, McMaster University, Hamilton, Canada, (2004)

[27] A Ghobarah, Performance based design in earthquake engineering: State of the development, Engineering Structures, 23, (2001), pp.878-884 